This item was submitted to Loughborough's Research Repository by the author.

Items in Figshare are protected by copyright, with all rights reserved, unless otherwise indicated.

\title{
The ambidextrous manager: What role does culture play?
}

\section{PLEASE CITE THE PUBLISHED VERSION}

http://dx.doi.org/10.1108/JBS-03-2016-0030

\section{PUBLISHER}

(C) Emerald

\section{VERSION}

AM (Accepted Manuscript)

\section{PUBLISHER STATEMENT}

This work is made available according to the conditions of the Creative Commons Attribution-NonCommercialNoDerivatives 4.0 International (CC BY-NC-ND 4.0) licence. Full details of this licence are available at: https://creativecommons.org/licenses/by-nc-nd/4.0/

\section{LICENCE}

CC BY-NC-ND 4.0

\section{REPOSITORY RECORD}

Hodgkinson, lan, Ravishankar Mayasandra-Nagaraja, and Michelle Aitken-Fischer. 2019. "The Ambidextrous Manager: What Role Does Culture Play?". figshare. https://hdl.handle.net/2134/21848. 


\title{
The ambidextrous manager: what role does culture play?
}

\author{
Journal of Business Strategy
}

\author{
Ian R. Hodgkinson, M.N. Ravishankar, Michelle Fischer
}

Loughborough University School of Business and Economics

\begin{abstract}
Purpose We know from research that the right context can help managers develop an ambidextrous approach. But just as few of us are naturally ambidextrous, many managers fail to balance conformity and change during strategy implementation. We investigate why.

Design/methodology/approach Through a qualitative study of managers of an international airline we examine a series of cultural barriers that constrain managers' agile decisionmaking and stop managerial ambidexterity.

Findings We identify 6 culturally-ingrained practices that block managerial ambidexterity: Top management's unwavering emphasis on cost-control when survival hinges on fresh investments; Little or no scanning of the environment for new areas of opportunity; Intensive planning oriented toward efficiency issues; Functional structures characterized by extensive division of labor; Centralized control; Formal hierarchical communication channels.

Research implications Managers find it difficult to put into practice new initiatives, particularly when the proposed initiatives counter the underlying cultural world of the organization. We suggest that this dark-side of culture can pose tough barriers for ambidextrous action.

Practical implications There is an urgent need for organizations to be aware of the possible misalignments between ambidextrous pursuits and the cultural forces that actually drive action. A deep understanding of their organization's cultural universe is a crucial first step for managers aspiring to better engage with ambidexterity and outwit and outperform competitors.

Originality Different strategic approaches need not be viewed as irreconcilable. If cultural elements don’t block it, managerial ambidexterity can showcase innovative approaches to reconciling trade-offs in strategic decision-making.
\end{abstract}

Paper type Research paper

Keywords Ambidexterity, Managerial ambidexterity, Culture, Barriers, Managers, Airline industry, Interviews.

\section{Ambidextrous managers?}

Conventional strategies often require a complete commitment to one course of action, which often results in over-allocation of resources and time to that particular strategy, leaving managers in no position to effectively switch to an alternative strategy when performance declines or when pressures from the environment demand a change. The uncertainty, 
unpredictability and volatility faced by decision-makers (McMillan and Overall, 2016) underscores the need for ambidextrous rather than conventional strategies.

We can think of ambidexterity as the pursuit of conflicting objectives simultaneously, such as the ability to move quickly toward new opportunities, adjust to volatile markets, and avoid complacency (i.e. adaptability), while also coordinating and streamlining activities in line with carefully designed plans (i.e. alignment). The world of sport provides some vivid examples of ambidexterity in action. In snooker, the five time-world champion Ronnie O'Sullivan, a right-handed player, is well-known for using his left-hand to generate new angles for performance gains; in cricket, batsmen increasingly play unorthodox reverse switch-hits and paddle scoops to alternate from orthodox attack and surprise opponents; in football, Leicester City has now acquired legendary status, not least because of its remarkable ambidextrous accomplishment - spending significantly less than their direct competitors and at the same time rising to the top of the English Premier League.

Ambidexterity, of course, is not the sole domain of competitive sport. Managers in a diverse range of business organizations have been the architects of ambidextrous courses of action. Toyota's simultaneous creation of superior efficiency and superior flexibility in its production system is a case in point (Adler et al., 1999). Managers in "great” companies such as Siemens, Royal Dutch Shell, and GlaxoSmithKline have managed to perform at a very high level over very long periods of time by leveraging existing assets while at the same time diversifying their supply bases, products, customers, and geographic markets (Stadler, 2007). Managers in Singapore Airlines are known to balance the supposedly incompatible strategies of differentiation and cost-leadership for advantage gains (Heracleous and Wirtz, 2010).

The main implication of these instances is that ambidexterity is not only possible, but when effective it catches even the best prepared competitor off guard. It increases the range of strategic actions available to organizations because ambidextrous managers possess the agility and flexibility to speedily respond to competitors' moves and to design innovative strategies in a rapidly changing environment. The simple idea behind its value is that modern managers always contend with conflicting objectives (e.g. investment in current versus future projects, efficiency versus flexibility, differentiation versus low-cost production, incremental innovation versus radical innovation, high-volume/low-margin versus low-volume/highmargin). Ambidextrous managers rise to the occasion and switch strategically and optimally between seemingly irreconcilable aspirations. They question blind conformity to tried and tested practices and help companies pursue new opportunities.

\section{Hurdles to ambidexterity: the dark side of culture}

Managers pursue change to enhance competitive positioning and to grow the organization. Simultaneously, they attempt to sustain competitive advantage by reducing uncertainty and securing continuity in exploiting available resources. We know from research that the right context can help managers develop an ambidextrous approach. But just as few of us are naturally ambidextrous, many managers fail to complement conformity with adaptability (Dover and Dierk, 2010). Why is this so? We interviewed managers at a leading international 
airline and found that more than problematic personality traits, a series of cultural barriers constrain managers' agile decision-making instincts and stop them from enacting ambidextrous behaviors.

Managers are often torn between conformity and change during strategy implementation. Such conflicts are particularly prominent in mid-life and mature firms where habits and routines become firmly embedded over time and direct what unfolds in the strategic decisionmaking process. So, managers are compelled to closely follow norms and the urge to 'not rock the boat' can seriously influence strategic decision-making. Culture represents a complex pattern of expectations, ideas, values, attitudes, and behaviors shared within an organization that evolve over time, and can reinforce a process of continuity. Because ambidexterity involves radically different activities, managers must be able to exercise their own judgment to effectively manage continuity and discontinuity simultaneously, which is difficult to achieve when cultural forces resist or oppose. In large well established firms the status quo is often encouraged and risky decision-making is rarely pursued by managers, which breeds a culture that focuses on minor operational modifications rather than the pursuit of radical change or new opportunities.

This is often symptomatic of failure in the competitive business arena. Take for instance the department store British Home Stores, which operated as an international franchise business for more than 30 years, yet seemingly became paralyzed by fear of failure and did not progress with the times, leading to its eventual collapse. Here, managers' unwavering, but futile commitment to the norms of traditional retailing came at the expense of adaptability (e.g. McMillan and Overall, 2016). A culture that privileges yesterday's practices at the expense of tomorrow is less inclined to fully support discontinuity and pragmatic adjustments in strategy implementation. Culturally-ingrained practices can explain why and how many managers fail to strike a balance between conformity and change in their decision-making. Next, drawing on our empirical study, we illustrate six classic cultural barriers to managerial ambidexterity.

\section{Our research setting}

AIRFLY (a pseudonym) is a leading international airline which has operated for over half a century. AIRFLY offers passenger services to about 200 global destinations in more than 60 countries. It employs more than 80000 employees from more than 100 nationalities and is also a major partner in a well-known international airline alliance network. Structurally, AIRFLY is organized into a handful of strategic business units (SBUs) through which it delivers a wide-range of passenger and cargo services. Managers at AIRFLY operate in a highly dynamic and competitive environment that increasingly demands both alignment of organizational activities to shared goals and adaptability to a dynamic environment.

We conducted in-depth interviews with 12 managers in five AIRFLY SBUs. Access to managers was negotiated by one of the authors who has worked as a consultant for many years in the aviation sector. All the interviews were digitally recorded and transcribed. In the main, the interviews featured questions about the importance of paradoxical strategic 
approaches and their drivers and enablers. An illustrative list of open-ended questions directed the flow of conversation with managers and also provided a flexible setting for exploring a wide-range of related issues. The managers were interviewed in the AIRFLY office of a major European city. Collectively, the interviewed managers covered a variety of business roles such as operational integration, sales and marketing, pricing, HR, training and development, airport management, brand management and management of premium services.

\section{Managerial ambidexterity ...to be, or not to be? A question of culture}

AIRFLY managers operate in a highly competitive and dynamic environment where adherence to strategic plans needs to be complemented by agility. They explained that despite all the carefully crafted strategic plans the airline often found itself facing a number of new challenges (as well as new opportunities). Adaptable and flexible approaches had to be employed almost every day for the airline to stay competitive. However, in their quest for ambidextrous decision making i.e., exploiting existing assets but also pursuing new opportunities with vigour, managers often had very limited success. They struggled to balance different demands and suggested that the culture of the airline constrained their attempts to act ambidextrously. Over a period of stable growth, AIRFLY had become overly rigid in its structure and dogmatic in its decision-making. Culturally, alignment was valued over adaptability, which limited opportunities for managers to effect a change of course in their strategic decision-making. Based on the findings from our interviews, we elaborate on six culturally-driven practices that frustrate and block managerial ambidextrous action:

\section{Top management's unwavering emphasis on cost-control when survival hinges on fresh investments}

You're always having senior management asking is this really necessary? How much does it cost? Can't we get somebody else to pay for it? And the usual cost and process discussion.

An excessive emphasis on caution and deliberation by "cost-control specialists" in top management teams can seriously impede the speed with which managers respond to changes in the business environment. Providing managers' the leeway to redeploy resources efficiently and effectively so new opportunities can be explored and/or threats neutralized is critical for managerial ambidexterity. However, when keeping costs low is the predominant cultural mantra within top management teams, it can thwart managers' creativity and agility. Even worse, in many cases it can leave managers facing punitive action if something goes awry, particularly when additional costs are incurred, which leads to a cultural message of “be careful and don’t do it”. So even if new strategies are adopted, processes still driven by the old way continue to push familiar practices.

Our corporate culture is 'if I do nothing I do not get into trouble, but if I do something and it's the wrong thing my neck's on the line'.

\section{Little or no scanning of the environment for new areas of opportunity}


The ability to gain insights from the market and use this information to adjust activities is central to effective adaptability. This requires the identification of opportunities and threats in the environment - a process ignited by proactive managerial thinking and action. However, a long period of stable growth can create an inward looking culture wherein strategic changes are triggered mostly in response to the moves of competitors.

AIRFLY would rather follow the leader, 'yes this is good, but let somebody else do it first and then we'll do it'.

A cultural predisposition to only support and cultivate knowledge that is already "accepted in the market" at the expense of responding to new knowledge can seriously undermine and frustrate managers' efforts to perform ambidextrous action. This is compounded by strategic guidelines that are only amended every 2-3 years, establishing cultural expectations that managers find impossible to change.

To be innovative is impossible when you're talking of time frames of 2 years.

\section{Intensive planning oriented toward efficiency issues}

Careful and elaborate strategic plans are of course necessary, but a culture that deifies planning and efficiencies can mean that course-corrections and adaptations are unlikely to be well-resourced:

So they say 'well, we're going to do this, but we've got to do it cheap', so therefore it's going to be quick and dirty and then of course it's not the perfect process and it's not the perfect solution....and this of course can lead people to give up quickly.

The hardest part of strategic management is to kill rigid processes and release human resources to where they are needed most. However, a recurring problem in environments where planning is sacrosanct is that resources are rarely available to support the implementation of strategic change: “AIRFLY couldn’t find any resources to do it”. Thus, managers' ability to pursue discontinuity and change can be heavily curtailed in a setting that glorifies planning and the maintenance of status quo for efficiency gains.

\section{Functional structures characterized by extensive division of labour}

Formal role prescriptions can impose rigidities that restrict managerial behavior to very specific types of action. Expected managerial behavior can become narrowly defined and decision-making bureaucratic, which in turn limits openness and creative problem solving (Pierce and Delbecq, 1977):

They tried to improve something in the HR department but it had to be implemented by the training department which had different interests and therefore there were a lot of conflicts...it became so many battles on so many battlefronts.

A sharing culture is an important means of allowing organizational members' views and opinions to be heard, for knowledge to be transferred, and for learning to occur, all of which 
encourage ambidextrous behavior. In contrast, narrowly-defined parameters of decisionmaking and extensive division of labor blocks the development of a shared culture and triggers internal conflicts of a political nature.

They [top management] say, 'this is your role so do it and don't come to me and complain about it'.

\section{Centralized control}

A centralized and top-down approach to decision-making shrinks managers to the part of foot soldiers, whose roles are restricted to executing strategy and not questioning it. Somewhat ironically, top management in highly centralized organizations tend to believe that their actions actually help make faster and more effective decisions. But when managerial input into organizational decision-making is limited it can have a detrimental impact on the ability and willingness of managers to quickly reconfigure activities to meet changing demands on a continuous basis. A high degree of centralization directs information to a small number of decision-makers in the environment, leaving many managers feeling left out. Such managers are more likely to go through the motions and less likely to demonstrate agility in their everyday work.

Colleagues just want to be told what to do.

Although they [top management] said 'we've got to do it together', they were running ahead with their strategy and expecting you to run after them.

\section{Communication through formal hierarchical channels}

A lack of horizontal communication channels and informal communication mechanisms constrains managers from generating enough momentum for strategic change and instead, reinforces commitment to conventional approaches.

They had thought that everybody knew what was going on and that wasn't the case...it hadn't dripped down through the communication system to the individual people who had this role.

In a culture that privileges a tightly-controlled formal communication apparatus, managers cannot rely on informal cues. In such environments, managers take fewer risks and follow the official script closely. This leaves managers feeling intimidated by the formality of the communication channels in place, which prohibits the expression of concerns and ideas out of fear of looking "stupid" or being perceived as "difficult".

No-one has the courage to say 'we have to change our strategy'.

While such a managerial approach could be a virtue in stable business environments, it almost certainly causes trouble in hypercompetitive and dynamic markets, wherein adaptability is at the heart of competitive advantage.

\section{Conclusion}


Ambidextrous managers play a crucial role in the superior competitive performance of organizations, but ambidextrous courses of action don't come naturally to managers. As outlined in this article, even when managers are alive to the evolving needs of the business environment, culturally embedded practices can block the way of managerial ambidexterity. They can promote persistence and rigidity when a pragmatic agile approach to decisionmaking is called for. Since the design of strategy is often disconnected from the individuals executing strategy, managers find it difficult to put into practice new initiatives, particularly when the proposed initiatives counter the underlying cultural world of the organization. We suggest that this dark-side of culture can focus way too much on maximizing today's value at the expense of tomorrows, posing tough barriers for ambidextrous action. We have identified six such culturally-ingrained practices:

- Top management's unwavering emphasis on cost-control when survival hinges on fresh investments;

- Little or no scanning of the environment for new areas of opportunity;

- Intensive planning oriented toward efficiency issues;

- Functional structures characterized by extensive division of labor;

- Centralized control;

- Communication through formal hierarchical channels.

At AIRFYLY, these practices supported alignment to carefully designed plans, but limited managers' ability to move quickly toward new opportunities, adjust to volatile markets, and avoid complacency. As the culture of AIRFLY developed over time it encouraged compliance to the wisdom of established rules rather than giving managers the psychological safety to flout norms. The unwillingness to move away from established logics manifested in debilitating "continuities of action" (McMillan and Overall, 2016). In other words, the cultural elements made it almost impossible to pause, reflect and change strategic course.

We invest huge, huge, huge amounts of money just on maintaining the monsters that we've built and the more monstrous they are, the more complicated they are to get rid of and bring in new technology.

Once "reliable systems" are identified, they can create an illusion of stability, and then it can be difficult to embrace change even when survival is at stake. Rigidities created through cultural forces often underpin decision-making paralysis and otherwise astute managers take refuge in denial:

My boss avoided noticing that we wouldn't meet the target although I'd been talking to him about it.

I think the biggest challenge that we're facing is our resistance to change, our fear of change as a company.

Different strategic approaches need not be viewed as irreconcilable or assumed to necessarily lead organizations into disarray. If cultural elements don't block it, managerial ambidexterity can showcase innovative approaches to reconciling trade-offs in strategic decision-making. 


\section{References}

Adler, P.S., Goldoftas, B., and Levine, D. I. (1999), "Flexibility versus efficiency? A case study of model changeovers in the Toyota production system”, Organization Science, Vol. 10 No. 1, pp. 43-68.

Birkinshaw, J. and Gibson, C. (2004), "Building ambidexterity into an organization”, MIT Sloan Management Review, Vol. 45 No. 4, p.47.

Dover, P.A. and Dierk, U. (2010), "The ambidextrous organization: integrating managers, entrepreneurs and leaders”, Journal of Business Strategy, Vol. 31 No. 5, pp.49-58.

Heracleous, L., and Wirtz, J. (2010), “Singapore airlines' balancing act”, Harvard Business Review, Vol. 88 No. 7/8, pp. 145-149.

McMillan, C. and Overall, J. (2016), "Wicked problems: turning strategic management upside down", Journal of Business Strategy, Vol. 37 No. 1, pp. 34-43.

Pierce, J.L. and Delbecq, A.L. (1977), "Organization structure, individual attitudes and innovation”, Academy of Management Review, Vol. 2 No. 1, pp. 27-37.

Stadler, C. (2007), “The four principles of enduring success”, Harvard Business Review, Vol. 85 No. 7/8, pp. 62-72. 